\title{
粉体粒径のモーメントに着目した粉砕機のモデリング*
}

\author{
深山 幸穂 ${ }^{* *}$ ・金氏 \\ 川瀬 隆世 ${ }^{* * * *}$ ・湯浅 \\ 武 $^{* * *}$ ・井山 \\ 博司 $^{* * * *} \cdot$ 山本 晃二****
}

\section{A Modeling Method for Pulverizers Using Moments of the Particle Size*}

\author{
Yukio Fukayama**, Takeshi Kaneuji ${ }^{* * *}$, Nozomu Iyama***, \\ Takayo Kawase ${ }^{* * * *}$, Hiroshi YuASA ${ }^{* * * *}$ and Koji Yamamoto****
}

\begin{abstract}
A dynamics model suitable for applying the system control theory to pulverizers has been developed. In this report, the dynamics model is discussed through the following order : (1) describing pulverizers, in which particle size distributions have the nonGaussian properties, with the state space form as stochastic systems, (2) reducing the order of the state space by the proposed parameterizing method using the moments of the particle size distributions, (3) deriving the modeling algorithms for the proposed method, and (4) validations of the model through analysis on a commercial plant and dynamics response data of a pilot plant.
\end{abstract}

\section{1.はじめに}

石炭火力発電設備は, 近年のエネルギ事情により増加 を続けており, 最近ではベースロード運用のみならず高 速負荷变化運用（従来は石油火力が担当）を求められて いる. 石炭火力用ボイラに抢いては，「石炭粉砕機とバー ナを直結して微粉炭を燃焼する方式」が主流であり，石 油火力 (バーナへの燃料供給量をバルブ操作で容易に制 御可能, 燃料が均質) 並みの負荷変化運用を実現するた め, 石炭粉砕機の制御が重要である.

石炭粉砕機の制御にあたり, バーナに供給される微粉 炭 (出炭) の粒度分布や流量の目標值への追従性が性能 評価の対象となる. このとき, 微粉炭の粒度分布は一般 に非ガウス性が強く, 燃料の品質として平均粒径よりあ 分布の裾（例： 80 パーセンタイル值で $75 \mu \mathrm{m}$ 程度）が 重視されている. 加えて, 出炭流量の变化は粉砕機内の

* 原稿受付 1994 年 1 月 10 日

** バブコック日立 林 呉研究所 Kure Research Laboratory, Babcock-Hitachi ; 3-36 Takaramachi, Kure city, Hiroshima 737, JAPAN

*** 電源開発 火力部 Thermal Power Department, Electric Power Development Co. Ltd. ; 15-1 Ginza 6chome, Chuo ward, Tokyo 104, JAPAN

**** バブコック日立秝呉工場 Kure Works, BabcockHitachi ; 6-9 Takaramachi, Kure city, Hiroshima 737, JAPAN

Key Words : stochastic system, modeling, simulation, pulverizer, particle size distribution.
諸機構 (混合, 粉砕, 分級等) での粒度分布変化の帰結 であり，乙れら非ガウス性の現象に忠実なモデル化が必 要である.

本研究では, Austin ら 1) 3) による粉砕機構の特性解 明（粉砕速度論に基づく体系的な研究）および, 正路, 迴ら ${ }^{4), 5)}$ による分級機構, 混合機構を含めた粉砕機の諸 特性の数值解析（粒度分布をヒストグラム状に分割して 非ガウス性を模擬）の成果に基礎を置き，新たなニーズ である「システム制御理論の応用に適するモデル」の 構築を推進した. 本論では, 粉砕機を確率システムとし て定式化（2.; 非ガウス性を状態空間で表現）した後, 粉体粒度分布のモーメントに着目した状態ベクトルの次 数低減, および, 乙の場合の粉砕機内諸機構の模擬方法 の提案（3.）を行い, 最後に新提案のモデルの妥当性を 確認 (4. ; 粉体流量, 粒度分布等の実測データを使用) する.

本研究の動機や数值例は火力発電用石炭粉砕機に関す るが，議論，手法は粉砕機全般に適用可能である.

\section{2. 粉碎機のモデル化}

本論では, Fig. 1 の微粉炭製造用粉砕機を具体例とし て，モデル化の議論を進める. 粉砕機は, 一般に，(1) 粉 砕機構 (pulverizing : ローラ, ボール, ハンマー等), （2）分級機構 (classifying: 粉砕機構による被粉砕物 から重力, 遠心力等で粗粒を分離), 循環流 (recircula- 


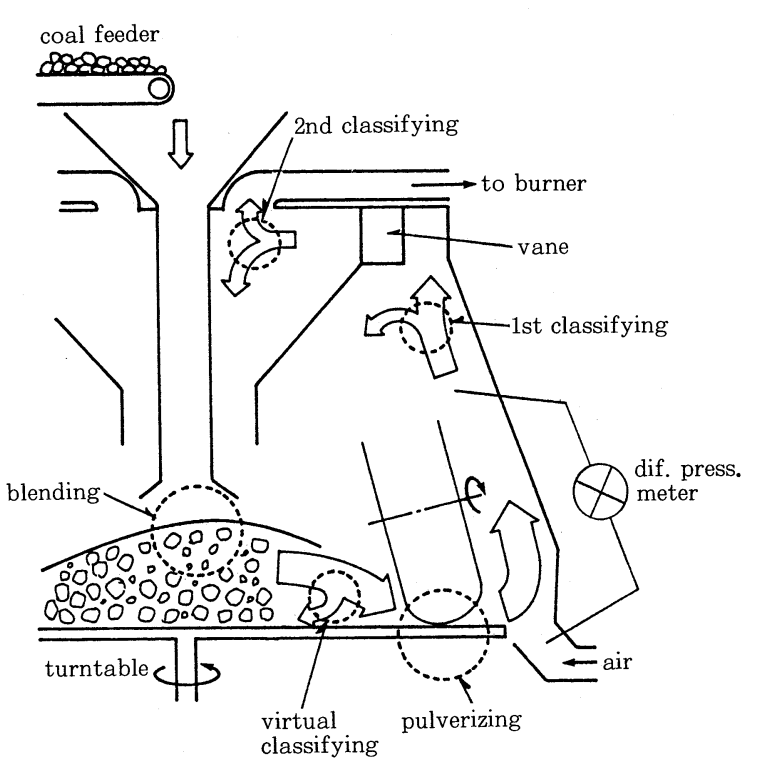

Fig. 1 Example of coal pulverizer

tion：分級機構から混合機構への粉体の流れ), (3) 混 合機構（blending：循環流と供給された原料を混合, 蓄積の後, 粉砕機構に流出), 蓄積 (hold-up : 混合機 構に保有する粉体）を主要な構成要素とする.

本例の粉砕機では, ベルトコンベアからの給炭は分級 機構からの循環流と共に, ターンテーブル（混合機構） 上で保有炭（蓄積）となり，外縁近傍のローラ（粉研機 構）て粉砕される. 粉砕後の石炭は搬送空気（ターンテー ブル外縁より供給）で吹き上げられ，一次分級（重力分 級機構), 抢よび, 二次分級 (遠心分級機構 ; 上部のベー ンによる旋回）で粗粒が捕集されて混合機構へ落下（循 環流）する. 他方，二次分級を通過した細粒は出炭とな り, バーナに供給される. また, 本研究では夕ーンテー ブル上の保有炭の粉砝機構入口への移動について, その 粒径依存性を効率的に考慮するため, 仮想的な分級機構 (virtual classifying : 2.3.2 参照) を仮定している.

\section{1 粒度分布の表記}

\subsection{1 粉体流の性質}

粉体中からサンプリングした 1 粒子について，その粒 径 $\Xi$ (以下, 大文字のスカラー, ベクトルは確率変数 を示す), 形状係数 $r$ (球形の場合 ; $=1$ ), 密度 $\Gamma$, 質量 $M$ は次の関係にある.

$$
M=\frac{1}{6} \pi \exp (3 \Xi) r \Gamma
$$

ここに, $\Xi$ は対数スケールで扱われ, 次の確率密度関 数 $f_{\Xi}(\xi)$ (以下, 確率密度関数全般を同様婊記する) を持つ.

$$
f_{\xi}(\xi) d \xi=\operatorname{Pr}\{\xi<\Xi \leqq \xi+d \xi\}
$$

また，粉体の流量 $Q$ （質量流量）は次のと抢り求めら れる。

$$
Q=\sum_{r=1}^{N} M
$$

乙こに, $N$ は断面（断面積 $S$ ) の単位時間の通過粒子 の個数で, 粒子の存在密度 $P$, 断面法線方向の速度成 分 $Z$ (両者と屯 $\Xi$ 亿依存）上り次のと扔り与えられる.

$$
N=P Z S
$$

\subsection{2 粒度分布の定義}

本研究では，粒度分布の定義に「断面を微小時間に通 過する粒子中の, 対数粒径 $\xi$ 以下なる質量割合」を用 い，その密度関数を $g(\xi)$ と表記（適宜に場所を示す添 字を付加）する. $g(\xi)$ と $f_{\Xi}(\xi)$ との関係は (1) 〜 (4) 式を考慮して，以下となる.

$$
\begin{aligned}
& g(\xi) \equiv E\{Q\}^{-1} E\{Q \mid \xi<\Xi \leqq \xi+\Delta \xi\} f_{\xi}(\xi) \\
& \quad=E\{P Z \exp (3 \Xi)\}^{-1} \\
& \quad \times \iint \rho \zeta f_{P Z \mid \Xi}(\rho, \zeta \mid \xi) d \rho d \zeta \\
& \quad \times \exp (3 \xi) f_{\Xi}(\xi)
\end{aligned}
$$

乙こに, $f_{P Z \mid \Xi}(\rho, \zeta \mid \xi)$ は $P, Z$ の結合条件付確率密度 （以下，条件付確率密度全般を同様に表記する）である.

(5) 式の定義により， $\xi<\Xi \leqq \xi+\Delta \xi$ なる粒子の流 量の期待値は $E\{Q\} g(\xi) \Delta \xi$ で表わせる.

粉体の移動速度 $E\{Z\}$ が小さい場合, $Z$ と $\Xi$ は独立 （粒径による速度差が小さい）とみなせ，(5) 式は次の 形式 $(E\{Z\}$ を約分した $)$ に帰着する.

$$
\begin{aligned}
& g(\xi)=E\{P \exp (3 \Xi)\}^{-1} \\
& \quad \times E\{P \mid \xi<\Xi \leqq \xi+\Delta \xi\} \exp (3 \xi) f_{\xi}(\xi)
\end{aligned}
$$

この形式により, 粒度分布 $g(\xi)$ を「静止した粉体」 に適用可能である. したがって, 混合機構に蓄積した粉

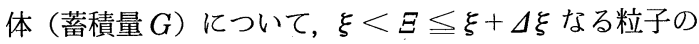
蓄積量の期待值は $E\{G\} g(\xi) \Delta \xi$ で表わせる.

\section{2 粉研機構}

粉砕前後の粒度分布（粉砕前後の諸量に，それぞれ添 字 ${ }_{i p, o p}$ を付加）は, 条件付確率密度 $g_{o p \mid i p}(\xi \mid \eta)$ を用 い, 一般に次の関係之置ける.

$$
g_{o p}(\xi)=\int g_{o p \mid i p}(\xi \mid \eta) g_{i p}(\eta) d \eta
$$

被粉砕物が石炭の場合, 正路 ( ${ }^{4)}$ により, 条件付確率 密度の関数形が解明され，次式のとおり粉砕前後の粒径 の比（対数粒径の差）のみへの依存性（流量 Qの影響 小；実験による）が知られている.

$$
g_{o p l i p}(\xi \mid \eta)=s(\xi-\eta)
$$

ここに, $s(\xi)$ は粉砕分布定数と呼ばれる. 
粉砕前後の質量流量の関係は，粉砕機構に蓄積作用は ない（蓄積作用は混合機構に一括して扱う）と仮定して 次式を得る。

$$
E\left\{Q_{o p}\right\}=E\left\{Q_{i p}\right\}
$$

(7) 〜 (9) 式より粉砕機構の模擬は次に帰着する.

$$
E\left\{Q_{o p}\right\} g_{o p}(\xi)=s(\xi) * E\left\{Q_{i p}\right\} g_{i p}(\xi)
$$

ここに，*は重畳積分を示す.

\section{3 分級機構}

\subsection{1 分級機構全般}

粉砕機中の $n+1$ 個の分級機構について，乙れを第 $j$ 番目で代表させ, 入口, 循環, 通過の各粉体流の諸量 (順に, 添字 ${ }_{i j, r j, t j}$ ) の関係を考える.

このとき, 部分分級効率 $c_{j}(\xi)$ を「粒径 $\xi$ 近傍の入 口流と循環流の比」として以下に定義する.

$$
\begin{aligned}
& c_{j}(\xi) \equiv\left[E\left\{Q_{i j}\right\} g_{i j}(\xi) \Delta \xi\right]^{-1} \\
& \quad \times E\left\{Q_{r j}\right\} g_{r j}(\xi) \Delta \xi \\
& 0 \leqq c_{j}(\xi) \leqq 1
\end{aligned}
$$

石炭粉砕機の場合, $c_{j}(\xi)$ の関数形は迴ら ${ }^{5)}$ により解明 されており, 粒径 $\Xi$ のへの依存性（流量 $Q$ の影響小; 実験による）が知られている.

循環流，通過流について，(11）式の定義より，ただ ちに以下の関係を得る.

$$
\begin{aligned}
& E\left\{Q_{r j}\right\} g_{r j}(\xi) \\
& \quad=c_{j}(\xi) E\left\{Q_{i j}\right\} g_{i j}(\xi) \\
& E\left\{Q_{t j}\right\} g_{t j}(\xi) \\
& \quad=\left[1-c_{j}(\xi)\right] E\left\{Q_{i j}\right\} g_{i j}(\xi)
\end{aligned}
$$

このとき, 流量の期待值は以下のと抢り求められる.

$$
\begin{aligned}
& E\left\{Q_{r j}\right\}=r_{j} E\left\{Q_{i j}\right\} \\
& E\left\{Q_{t j}\right\}=\left(1-r_{j}\right) E\left\{Q_{i j}\right\}
\end{aligned}
$$

ここに，循環比 $r_{j}$ を次のとおり定義した.

$$
r_{j} \equiv \int c_{j}(\xi) g_{i j}(\xi) d \xi
$$

\subsection{2 仮想分級機構（粉砕速度定数の取り扱い）}

「混合機構の粉体の蓄積量 $G_{b}$ 之粉砕機構への流出流 量 $Q_{i p}$ の比」は, 粉砕速度定数 $b(\xi)$ として次式に定義 される.

$$
\begin{aligned}
& b(\xi) \equiv\left[E\left\{G_{b}\right\} g_{b}(\xi) \Delta \xi\right]^{-1} \\
& \quad \times E\left\{Q_{i p}\right\} g_{i p}(\xi) \Delta \xi
\end{aligned}
$$

ここに, 石炭粉砕機の場合, $b(\xi)$ の関数形は正路 ${ }^{4)}$ ら により解明され, 粒径 $\Xi$ のへの依存性（蓄積量 $G$ の 影響小；実験による）が知られている.

本研究では後述する利便性 $\left(E\left\{G_{b}\right\} g_{b}(\xi)\right.$ 消去など) のため, $b(\xi)$ の粒径依存性を仮想的な分級機構（0番
目の分級機構）にて考慮する.乙れは，まず次式のとお り, 混合機構の蓄積量と仮想分級への流出量を比例関係 （粒径に非依存）とする.

$$
\begin{aligned}
& E\left\{Q_{i 0}\right\} g_{i 0}(\xi) \Delta \xi \\
& =\theta E\left\{\dot{G_{b}}\right\}_{g_{b}}(\xi) \Delta \xi
\end{aligned}
$$

ここに, 比例定数 $\theta$ は次に定める.

$$
\theta \equiv \sup \{b(\xi)\} \quad(\theta>0)
$$

つぎに, 下式の部分分級効率 $c_{0}(\xi)$ を持つ仮想分級機構 を置き（2.3.1の諸式を適用)，（20）式の（18）式に対す る粉体流の剩余分を混合機構へ循環させる.

$$
c_{0}(\xi) \equiv 1-\theta^{-1} b(\xi) \quad\left(0 \leqq c_{0}(\xi) \leqq 1\right)
$$

そして, 次式のとおり仮想分級機構の出口（通過）の条 件を粉砕機構入口に与え, $b(\xi)$ の粒径依存性の考慮を 完了できる.

$$
E\left\{Q_{i p}\right\} g_{i p}(\xi)=E\left\{Q_{t 0}\right\} g_{t 0}(\xi)
$$

\section{4 混合機構}

混合機構 $\left(\right.$ 添字 $\left.{ }_{b}\right)$ において, 分級機構 $(j=0, \cdots, n)$ からの循環流 (添字 $r j$ ) と, 原料 (添字 ${ }_{i b}$ ) とを混合, 蓄積の後, 仮想分級機構 (添字 ${ }_{i 0}$ ) に流出する場合, 諸 量の関係を考える.

混合, 蓄積により各粒子の粒径は変化しないと仮定し, 次のと打り, 粒径 $\xi<\Xi \leqq \xi+\Delta \xi$ の粒子のマスバラ ンス式が得られる.

$$
\begin{aligned}
& d E\left\{G_{b}\right\} g_{o b}(\xi) \Delta \xi \\
&= {\left[\sum_{j=0}^{n} E\left\{Q_{r j}\right\} g_{r j}(\xi)+E\left\{Q_{i b}\right\} g_{i b}(\xi)\right.} \\
&\left.-E\left\{Q_{i 0}\right\} g_{i 0}(\xi)\right] \Delta \xi d t
\end{aligned}
$$

(19) 式により, $E\left\{G_{b}\right\} g_{b}(\xi)$ を消去すれば, マスバ ランスは次式（粉体流のみに着目）となる.

$$
\begin{array}{rl}
\theta^{-1} & d E\left\{Q_{i 0}\right\} g_{i 0}(\xi) \\
= & {\left[\sum_{j=0}^{n} E\left\{Q_{r j}\right\} g_{r j}(\xi)+E\left\{Q_{i b}\right\} g_{i b}(\xi)\right.} \\
& \left.-E\left\{Q_{i 0}\right\} g_{i 0}(\xi)\right] d t
\end{array}
$$

\section{5 モデルの全体構成}

\subsection{1 モデル化対象について補足事項}

Fig. 1 の石炭粉砕機（仮想分級, 一次分級, 二次分 級の順に $j=0,1,2)$ のモデル化にあたり, 構造上から 以下の条件を補う。（粉砕機構出口加ら一次分級機構入 口，一次分級機構出口から二次分級機構入口への接続）

$$
\begin{aligned}
& E\left\{Q_{i 1}\right\} g_{i 1}(\xi)=E\left\{Q_{o p}\right\}_{o p}(\xi) \\
& E\left\{Q_{i 2}\right\} g_{i 2}(\xi)=E\left\{Q_{t 1}\right\} g_{t 1}(\xi)
\end{aligned}
$$


また，系の入力に関し，粉砤機への給炭量 $Q_{i b}$ (ベル トコンベアで供給）は, ベルト上の層高の「ゆらぎ」か ら確率変数となる. 一方, 給炭の粒度分布 $g_{i b}(\xi)$ は, 同一解析条件で一定（確率变数でない）と仮定できる. これは, ベルト上での粉体の移動速度は粒径に依存しな い（(5) 式と（6) 式が等価）から， $g_{i b}(\xi)$ は給炭の静 止時の粒度分布に等しく, かつ, 経験的に給炭の静止時 の粒度分布は打打む权一様だからである。

\subsection{2 システム方程式}

システム方程式の導出にあたり，2.2〜2.4 の諸式を （24）式に代入（Fig.1の粉体の流れに準拠）して次式 を得る.

$$
\begin{aligned}
d E & \left\{Q_{i 0}\right\} g_{i 0}(\xi) \\
= & \theta\left[\left[c_{2}(\xi)\left\{1-c_{1}(\xi)\right\}+c_{1}(\xi)\right]\right. \\
& \times\left[s(\xi) *\left[\left\{1-c_{0}(\xi)\right\} E\left\{Q_{i 0}\right\} g_{i 0}(\xi)\right]\right] \\
& +\left\{c_{0}(\xi)-1\right\} E\left\{Q_{i 0}\right\} g_{i 0}(\xi) \\
& \left.+E\left\{Q_{i b}\right\} g_{i b}(\xi)\right] d t \\
E\left\{Q_{t 2}\right\} g_{t 2}(\xi) & \\
= & {\left[\left\{1-c_{2}(\xi)\right\}\left\{1-c_{1}(\xi)\right\}\right] } \\
& \times\left[s(\xi) *\left[\left\{1-c_{0}(\xi)\right\} E\left\{Q_{i 0}\right\} g_{i 0}(\xi)\right]\right]
\end{aligned}
$$

乙のとき，(27)，(28）式に扔いて Qの期待値記号を 除去し, 次の確率システムを考える.

$$
\begin{aligned}
& d Q_{i 0} g_{i 0}(\xi)=\left[A\left\{g_{i 0}(\xi)\right\} Q_{i 0}\right. \\
& \left.\quad+B\left\{g_{i b}(\xi)\right\} u\right] d t+B\left\{g_{i 0}(\xi)\right\} d \beta \\
& Q_{t 2} g_{t 2}(\xi)=C\left\{g_{i 0}(\xi)\right\} Q_{i 0}
\end{aligned}
$$

乙こに, 次の演算 $A, B, C$ を定義した.

$$
\begin{aligned}
& A\{g(\xi)\} \equiv \theta\left[c_{2}(\xi)\left\{1-c_{1}(\xi)\right\}+c_{1}(\xi)\right] \\
& \quad \times\left[s(\xi) *\left[\left\{1-c_{0}(\xi)\right\} g(\xi)\right]\right] \\
& \quad+\theta\left\{c_{0}(\xi)-1\right\} g(\xi) \\
& B\{g(\xi)\} \equiv \theta \\
& C\{g(\xi)\} \equiv\left[\left\{1-c_{2}(\xi)\right\}\left\{1-c_{1}(\xi)\right\}\right] \\
& \quad \times\left[s(\xi) *\left[\left\{1-c_{0}(\xi)\right\} E\left\{Q_{i 0}\right\} g(\xi)\right]\right]
\end{aligned}
$$

また, $\beta$ は分散パラメータ $R_{W}$ のブラウン運動で, 次 の性質を持つ.

$$
\begin{array}{ll}
Q_{i b}=u+W & \\
W d t=d \beta & \\
E\{\beta(t)-\beta(s)\}=0 & \text { (すべての } t, s) \\
\operatorname{Var}\{\beta(t)-\beta(s)\} & \\
\quad=R_{W}|t-s| & \text { (すべての } t, s)
\end{array}
$$

ここで, 演算 $A, B, C$ は直接的に $Q$ 亿非依存であり, $g(\xi)$ を介して緩慢に変化する.ささらに，(3) 式におけ る中心極限定理の成立（ $N$ は十分大）を期待して，(29）,
（30）式は流量 $Q$ について線形時変ガウス性システムと みなせる.よって, その解の平均値関数が (27)，(28) 式に従う確率システムは, 唯一 (29), (30) 式であり, これが求める粉研機の定式化である.

なお，オンライン制御での利便性により， $Q_{i b}$ は計測 信号 $u$ に白色雑音 $W$ (ベルトコンベアの動特性の影響 等で有色雑音となる場合は, 適宜, 当該動特性をシステ ム方程式に組み込む9 $\left.{ }^{9}\right)$ が加算されたと仮定する.

\section{3. 粉碎機モデルの次数低減}

状態ベクトル ((27) 式) の数值計算にあたり, 関数 空間のヒストグラム状の近似 $\left(x\left(\xi_{1}\right), x\left(\xi_{2}\right), \cdots, x\left(\xi_{l}\right)\right)^{\mathrm{T}}$ を採用すると, 模擬精度の確保のため, 経験的に数十次 元を要し, 少なくと屯制御技術用として実用的ではない. このため, 本節では状態ベクトルの次元低減法と, その 際の粉碎機内の諸機構の模擬方法を導出し, 実用的な粉 砕機モデルを構築する.

な报, 粒度分布密度 $g(\xi)$, 粉䂶分布定数 $s(\xi)$ 亿つい て, レ 次以下のモーメントの存在を仮定して議論を進める.

\section{1 低次元化した状態ベクトルの性質}

\subsection{1 基準化したモーメントによる記述}

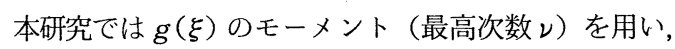
状態ベクトル $(Q g(\xi)$ 型) を以下のと抽年ラメトラ イズして $\nu+1$ 次 $(Q v(\lambda, \rho)$ 型) に次数の低減をはかる.

$$
Q \boldsymbol{v}(\lambda, \rho) \equiv \int \boldsymbol{q}\left(\rho^{-1}[\xi-\lambda]\right) Q g(\xi) d \xi
$$

こてに, 次のモーメントベクトル $v(\lambda, \rho)$, 多項式ベク トル $\boldsymbol{q}(\xi)$ をそれぞれ定義した。

$$
\begin{gathered}
\boldsymbol{v}(\lambda, \rho) \equiv\left(v_{0}(\lambda, \rho), v_{1}(\lambda, \rho), \cdots, v_{\nu}(\lambda, \rho)\right)^{\mathrm{T}} \\
\quad\left(v_{0}(\lambda, \rho)=1\right) \\
\boldsymbol{q}(\xi) \equiv\left(1, \xi, \cdots, \xi^{\nu}\right)^{\mathrm{T}}
\end{gathered}
$$

すなわち, $\boldsymbol{v}(\lambda, \rho)$ の第 $k$ 成分 $(k=0,1, \cdots, \nu)$ は, $(\lambda, \rho)$ 亿基準化（以下，変数変換 $\rho^{-1}[\xi-\lambda]$ を $\Gamma(\lambda, \rho)$ で基準化した」と称す）した $g(\xi)$ の $k$ 次モーメント $v_{k}(\lambda, \rho)$ であり, $\boldsymbol{v}(\lambda, \rho)$ と流量 $Q$ との積（以下，単に 流量 $Q v$ 之称し, 必要に応じて場所の添字を付加する) で対象システムを記述する。

ちなみに，以下の諸計算に扔いて $Q \boldsymbol{v}$ の形態で值を得 た場合， $v_{0}(\lambda, \rho)=1$ 亿着目して $Q$ と $v$ を一意に分離 できる.

\subsection{2 基準化パラメータの変更}

$\boldsymbol{q}(\xi), \boldsymbol{v}$ の基準化の変更について, 二項定理により次 の関係が成立する.

$$
\begin{aligned}
& \boldsymbol{q}\left(\rho^{-1}[\xi-\lambda]\right) \\
& \quad=L\left(\lambda, \rho ; \lambda_{0}, \rho_{0}\right) \mathbf{q}\left(\rho_{0}^{-1}\left[\xi-\lambda_{0}\right]\right)
\end{aligned}
$$




$$
\boldsymbol{v}(\lambda, \rho)=L\left(\lambda, \rho ; \lambda_{0}, \rho_{0}\right) v\left(\lambda_{0}, \rho_{0}\right)
$$

乙てに, 変換行列 $L\left(\lambda, \rho ; \lambda_{0}, \rho_{0}\right)=\left(l_{i j}\right)(i, j=0,1$, $\cdots, \nu)$ は次のとおり定義でき，正則行列となる.

(1) $j>i ; l_{i j} \equiv 0$

(2) $j \leqq i$;

$$
l_{i j} \equiv \rho_{0}^{i} \rho^{-i}{ }_{i} C_{j}\left[\rho_{0}^{-1}\left[\xi-\lambda_{0}\right]\right]^{i-j}
$$

なお， $(\lambda, \rho)=(\mu, \sigma) \equiv\left(v_{1}(0,1), v_{2}(\mu, 1)^{0.5}\right)$ と選べ ば，基準化した高次モーメントが減少し，解析精度が向 上する. 乙の場合, 次の関係が得られる.

$$
v_{1}(\mu, \sigma)=0, v_{2}(\mu, \sigma)=1
$$

\subsection{3 分布の混合}

$Q \boldsymbol{v}$ によるシステム記述の例として, 次の分布の混合 を考える.

$$
Q g(\xi)=\sum_{m} Q_{m} g_{m}(\xi)
$$

上式に $\boldsymbol{q}\left(\rho^{-1}[\xi-\lambda]\right)$ を乗じ, $-\infty<\xi<\infty$ につて 積分すれば，次の簡単な表記に帰着する.

$$
Q \boldsymbol{v}(\lambda, \rho)=\sum_{m} Q_{m} \boldsymbol{v}_{m}(\lambda, \rho)
$$

\subsection{4 密度関数の具体化}

$Q v(\lambda, \rho)$ から $Q g(\xi)$ 型への具体化は, グラム $=$ シャ リエ展開に基づき, $\boldsymbol{q}(\xi)$, 定数行列 $K$ (正則行列) を 用いて以下のとおり ${ }^{6)}$ 実施できる.

$$
\begin{aligned}
& Q g(\xi)=p(\xi ; \lambda, \rho) \\
& \quad \times \boldsymbol{q}^{\mathrm{T}}\left(\rho^{-1}[\xi-\lambda]\right) K Q \boldsymbol{v}(\lambda, \rho) \\
& K \equiv H^{\mathrm{T}} \operatorname{diag}\left(1,1,2 !^{-1}, \cdots, \nu !^{-1}\right) H
\end{aligned}
$$

ここに, $p(\xi ; \lambda, \rho)$ はガウス分布密度関数である.

$$
\begin{aligned}
& p(\xi ; \lambda, \rho) \\
& \quad \equiv(2 \pi)^{-0.5} \rho^{-1} \exp \left\{0.5 \rho^{-2}[\xi-\lambda]^{2}\right\}
\end{aligned}
$$

また, 定数行列 $H=\left(h_{i j}\right)(i, j=0,1, \cdots, \nu)$ は以下に 与えられ ${ }^{6)}$, 正則行列である.

$$
\begin{array}{ll}
\text { (1) } & j>i \text { or } i=2 n, j=2 k+1 \\
& \text { or } i=2 n+1, j=2 k ; h_{i j} \equiv 0 \\
\text { (2) } & j \leqq i, i=2 n+1, j=2 k+1 ; \\
& h_{i j} \equiv(-1)^{n-k} C_{k}(2 n+1) ! !\{(2 k+1) ! !\}^{-1} \\
\text { (3) } & j \leqq i, i=2 n, j=2 k ; \\
& h_{i j} \equiv(-1)^{n-k} C_{k}(2 n-1) ! !\{(2 k-1) ! !\}^{-1}
\end{array}
$$

乙のとき, $H \boldsymbol{q}(\xi)$ の第 $k$ 成分 $(k=0,1, \cdots, \nu)$ は, $k$ 次のエルミート多項式であり, 下式の直交性が知られて いる.

$$
\begin{aligned}
& \int H \boldsymbol{q}(\xi) \boldsymbol{q}^{\mathrm{T}}(\xi) H^{\mathrm{T}} p(\xi ; 0,1) d \xi \\
& =\operatorname{diag}(1,1,2 !, \cdots, \nu !)
\end{aligned}
$$

したがって，(47) 式に左より $H \boldsymbol{q}\left(\rho^{-1}[\xi-\lambda]\right)$ を乗じ, $\xi$ そいて積分すると次式が得られ，その第 $k$ 成分 $(k=0,1, \cdots, \nu)$ は $k$ 次のグラム $=$ シャリ工展開係数で ある.

$$
\begin{aligned}
& H Q \boldsymbol{v}(\lambda, \rho) \\
& \quad=\int Q g(\xi) H \boldsymbol{q}\left(\rho^{-1}[\xi-\lambda]\right) d \xi
\end{aligned}
$$

なお，本論において $Q g(\xi)$ 型のグラフを表示する場 合, $(\lambda, \rho)=(\mu, \sigma)$ として (47) 式の打切䛊差（ $\nu$ 次を 越える項の影響) を低減する.

\section{2 粉砕機構}

粉砕機構における粒度分布変化は重畳積分（2.2）で あり，キュムラントの和で簡明に取り扱える.

$$
\kappa_{k o p}=\kappa_{k i p}+\kappa_{k s} \quad(k=1,2, \cdots, \nu)
$$

乙こに, $\kappa_{k o p}, \kappa_{k i p}, \kappa_{k s}$ は, 順に, 粉砕機構出口, 入口 の粒度分布密度 $g_{o p}(\xi), g_{i p}(\xi)$, 打よび, 粉砕分布定 数 $s(\xi)$ の $k$ 次キュムラントである. 乙のとき,一般に, $k$ 次キュムラント $\kappa_{k}$ は, モーメント $v_{m}(\lambda, \rho) \quad(m \leqq k)$ 之相互変換可能6) だから, 以下 $(k \leqq 5$ の具体例 $)$ のと おり粉砕機構を模擬できる.

まず，粉砕機構入口流量について，(53）式に与える キュムラント $\kappa_{k i p}$ を求める.

$$
\begin{aligned}
& \kappa_{1 i p}=\mu_{i p}=v_{1 i p}(0,1) \\
& \kappa_{2 i p}=\sigma_{i p}^{2}=v_{2 i p}\left(0, \mu_{i p}\right) \\
& \kappa_{3 i p}=\sigma_{i p}^{3} v_{3 i p}\left(\mu_{i p}, \sigma_{i p}\right) \\
& \kappa_{4 i p}=\sigma_{i p}^{4}\left[v_{4 i p}\left(\mu_{i p}, \sigma_{i p}\right)-3\right] \\
& \kappa_{5 i p}=\sigma_{i p}^{5}\left[v_{5 i p}\left(\mu_{i p}, \sigma_{i p}\right)-10 v_{3 i p}\left(\mu_{i p}, \sigma_{i p}\right)\right]
\end{aligned}
$$

なお， $\kappa_{k s}$ む $s(\xi)$ のーメントベクトル $\boldsymbol{v}_{s}$ から同様に 算出できる.

つぎに, 出口流量 $Q_{o p}, \boldsymbol{v}_{o p}$ は, (53) 式の算出結果を 用い，下式で求められる.

$$
\begin{aligned}
& \mu_{o p}=\kappa_{1 o p}, \sigma_{o p}=\kappa_{2 o p}^{0.5} \\
& v_{0 o p}\left(\mu_{o p}, \sigma_{o p}\right)=v_{2 o p}\left(\mu_{o p}, \sigma_{o p}\right)=1 \\
& v_{1 o p}\left(\mu_{o p}, \sigma_{o p}\right)=0 \\
& v_{3 o p}\left(\mu_{o p}, \sigma_{o p}\right)=\sigma_{o p}^{-3} \kappa_{3 o p} \\
& v_{4 o p}\left(\mu_{o p}, \sigma_{o p}\right)=\sigma_{o p}^{-4} \kappa_{4 o p}+3 \\
& v_{5 o p}\left(\mu_{o p}, \sigma_{o p}\right)=\sigma_{o p}^{-5} \kappa_{5 o p}+10 \sigma_{o p}^{-3} \kappa_{3 o p} \\
& Q_{o p}=Q_{i p}
\end{aligned}
$$

したがって，(53)〜（64）式の手順を関数 $\boldsymbol{v}_{o p}\left(\boldsymbol{v}_{i p}\right)$ で 代表させると, 粉砕機構の模擬は下式に帰着する.

$$
Q_{o p} v_{o p}=Q_{i p} v_{o p}\left(\boldsymbol{v}_{i p}\right)
$$




\section{3 分級機構}

分級機構における粒度分布，流量の変化は，それぞれ， 粒度分布密度 $g(\xi)$ 之部分分級効率 $c(\xi)$ の積，および, その積分 (2.3) で求められる. 本項では, てれらの演 算を, $Q v(\lambda, \rho)$ 亡 $c(\xi)$ のパラメータのみ（具体的な 関数值の積, 数值積分によるモーメント算出を不使用) により実施する.

\subsection{1 部分分級効率の近似}

部分分級効率 $c(\xi)$ は, 一般に, $0 \leqq c(\xi) \leqq 1$ を満 たす任意の連続関数（累積分布型関数の場合が多い）で あり，実用上の粉体粒径の範囲 $\xi_{a} \leqq \xi \leqq \xi_{b}$ について, $c(\xi)$ を, 適当なパラメータ $a_{m}, \lambda_{m}, \rho_{m}(m=1,2, \cdots)$ を用い, ガウス分布密度 $p(\xi ; \lambda, \rho)$ 型の関数の和で次 式に近似する.

$$
c(\xi)=\sum_{m} a_{m} p\left(\xi ; \lambda_{m}, \rho_{m}\right)
$$

このとき, 以下の諸量を定義し, $c^{[m]}(\xi)$ の゙ラフの概 形から $d_{m}$ （ $m$ 回目の近似手順による誤差の低減量）を 可能な限り大とするパラメータ $\left(a_{m}, \lambda_{m}, \rho_{m}\right)$ を決定す る.

$$
\begin{gathered}
c^{[m]}(\xi) \equiv c^{[m-1]}(\xi)-a_{m} p\left(\xi ; \lambda_{m}, \rho_{m}\right), \\
\left(m=1,2, \cdots ; c^{[0]}(\xi)=c(\xi)\right) \\
d_{m} \equiv \int_{\xi a}^{\xi b}\left|c^{[m-1]}(\xi)\right| d \xi-\int_{\xi a}^{\xi b}\left|c^{[m]}(\xi)\right| d \xi \\
\varepsilon_{m} \equiv \sup \left\{\left|c^{[m]}(\xi)\right|\right\}, \quad\left(\xi_{a} \leqq \xi \leqq \xi_{b}\right)
\end{gathered}
$$

乙の手順を $\varepsilon_{m}$ が必要な値に低減できるまで繰り返し， 近似 $\left(a_{m}, \lambda_{m}, \rho_{m}\right.$ による $c(\xi)$ のパラメトライズ $)$ を完 了する.

Fig. 2 は第 $j$ 番目の分級機構についての以上の手法 の実施例であり, $c_{j}(\xi)$ (狭義単調増加の場合), 抢よび,
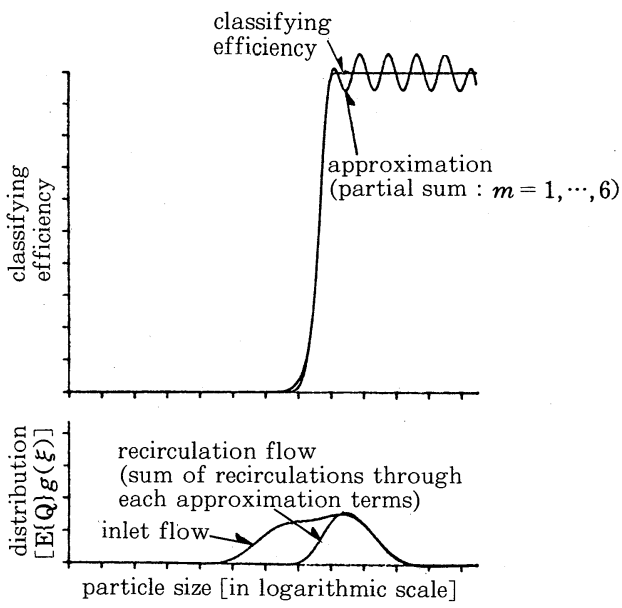

Fig. 2 Simulation method for the classifying process

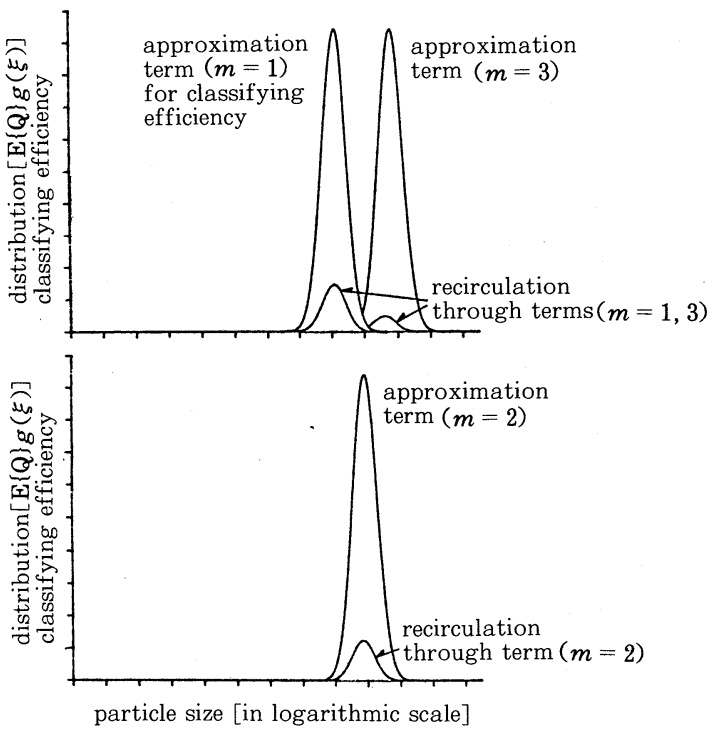

Fig. 3 Recirculations through approximation terms

その近似関数の部分和 ((67) 式; 近似成分の上位 6 項) を 示す. 本例では, $c_{j}(\xi)$ の第 $m$ 次近似成分 $(m=1,3$ : Fig. 3 上段， $m=2$ : 下段等）に起因する凹凸（左か ら順に $m=1,2, \cdots, 6$ の影響）が認められるが，さら に高次の近似成分 $\left(a_{m}<0\right.$ の場合あり) の付加により, 必要な近似精度を達成できる。なお，本項の各近似成分 は，対応する循環流量成分（求める循環流量 : 各流量 成分の加算）算出に使用し，その具体例を後述する.

\subsection{2 循環流量の算出法}

第 $j$ 番目の分級機構について，入口流量 $Q_{i j} \boldsymbol{v}_{i j}$ と分 級のパラメータ $\left(a_{m j}, \lambda_{m j}, \rho_{m j}\right)$ から循環流量 $Q_{r j} v_{r j}$ を 求める.すなわち，(13）式に(47)，(67）式を適用し, 次式のとおり $Q_{r j} v_{r j}$ と $Q_{i j} \boldsymbol{v}_{i j}$ との関係を導く.

$$
\begin{aligned}
p(\xi & ; \lambda, \rho) \boldsymbol{q}^{\mathrm{T}}\left(\rho^{-1}[\xi-\lambda]\right) K Q_{r j} \boldsymbol{v}_{r j}(\lambda, \rho) \\
= & {\left[\sum_{m} a_{m j} p\left(\xi ; \lambda_{m j}, \rho_{m j}\right)\right] } \\
& \times p\left(\xi ; \mu_{i j}, \sigma_{i j}\right) \\
& \times \boldsymbol{q}^{\mathrm{T}}\left(\sigma_{i j}^{-1}\left[\xi-\mu_{i j}\right]\right) \\
& \times K Q_{i j} \boldsymbol{v}_{i j}\left(\mu_{i j}, \sigma_{i j}\right)
\end{aligned}
$$

上式について，まず，以下の変形を行い，(71) 式の 右辺を分布の混合に帰着させる。

((71) 式の右辺)

$$
\begin{aligned}
= & \sum_{m} a_{m j}^{\sharp} p\left(\xi ; \lambda_{m r j}, \rho_{m r j}\right) \\
& \times \boldsymbol{q}^{\mathrm{T}}\left(\sigma_{i j}^{-1}\left[\xi-\mu_{i j}\right]\right) \\
& \times K Q_{i j} \boldsymbol{v}_{i j}\left(\mu_{i j}, \sigma_{i j}\right) \\
= & \sum_{m} a_{m j}^{\#} p\left(\xi ; \lambda_{m r j}, \rho_{m r j}\right)
\end{aligned}
$$




$$
\begin{aligned}
& \times \boldsymbol{q}^{\mathrm{T}}\left(\rho_{m r j}^{-1}\left[\xi-\lambda_{m r j}\right]\right) \\
& \times L^{\mathrm{T}}\left(\mu_{i j}, \sigma_{i j} ; \lambda_{m r j}, \rho_{m r j}\right) \\
& \times K Q_{i j} \boldsymbol{v}_{i j}\left(\mu_{i j}, \sigma_{i j}\right) \\
= & \sum_{m} p\left(\xi ; \lambda_{m r j}, \rho_{m r j}\right) \\
& \times \boldsymbol{q}^{\mathrm{T}}\left(\rho_{m r j}^{-1}\left[\xi-\lambda_{m r j}\right]\right) \\
& \times K Q_{m r j} \boldsymbol{v}_{m r j}\left(\mu_{m r j}, \sigma_{m r j}\right)
\end{aligned}
$$

ここに, 1 回目の変形において, $p(\xi ; \mu, \sigma)$ 型関数の 指数関数部に着目し, 次の条件を適用した.

$$
\begin{aligned}
& a_{m j}^{\#}=a_{m j} \\
& \quad \times \exp \left\{-0.5\left(\sigma_{i j}^{2}+\rho_{m j}^{2}\right)^{-1}\left(\mu_{i j}-\lambda_{m j}\right)^{2}\right\} \\
& \lambda_{m r j}=\left(\sigma_{i j}^{2}+\rho_{m j}^{2}\right)^{-1}\left(\rho_{m j}^{2} \mu_{i j}+\sigma_{i j}^{2} \lambda_{m j}\right) \\
& \rho_{m r j}=\left(\sigma_{i j}^{2}+\rho_{m j}^{2}\right)^{-0.5} \rho_{m j} \sigma_{i j}
\end{aligned}
$$

また, 2 回目の変形では (41) 式を, さらに, 3 回目の変 形では次の $Q_{m r j} \boldsymbol{v}_{m r j}$ を用いた.

$$
\begin{aligned}
& Q_{m r j} \boldsymbol{v}_{m r j}\left(\mu_{m r j}, \sigma_{m r j}\right) \\
& \equiv a_{m j}^{\#} K^{-1} L^{\mathrm{T}}\left(\mu_{i j}, \sigma_{i j} ; \lambda_{m r j}, \rho_{m r j}\right) \\
& \quad \times K Q_{i j} \boldsymbol{v}_{i j}\left(\mu_{i j}, \sigma_{i j}\right)
\end{aligned}
$$

よって, (71) 式の左辺と（72）式に着目し，結論の式 $\left(Q_{r j} \boldsymbol{v}_{r j}\right.$ と $Q_{i j} \boldsymbol{v}_{i j}$ の関係) が得られる.

$$
\begin{aligned}
Q_{r j} \boldsymbol{v}_{r j}(\lambda, \rho) & =\sum_{m} Q_{m r j} \boldsymbol{v}_{m r j}(\lambda, \rho) \\
& =J_{r j} Q_{i j} \boldsymbol{v}_{i j}\left(\mu_{i j}, \sigma_{i j}\right)
\end{aligned}
$$

ここに，第 $j$ 番目の分級機構循環流の算出行列 $J_{r j}(Q$ に非依存）を定義した。

$$
\begin{aligned}
J_{r j} \equiv & \sum_{m} a_{m j}^{\#} L\left(\lambda, \rho ; \lambda_{m r j}, \rho_{m r j}\right) \\
& \times K^{-1} L^{\mathrm{T}}\left(\mu_{i j}, \sigma_{i j} ; \lambda_{m r j}, \rho_{m r j}\right) K
\end{aligned}
$$

なお， $K, L$ はそれぞれ，(48)，(43) 式より与えられ， 正則行列である.

本手法の適用例として, Fig. 2, 3(確率変数 $Q$ は $E\{Q\}$ で表示) は, 部分分級効率 $c_{j}(\xi)$ (Fig. 2 上段), 入口流量 $Q_{i j} \boldsymbol{v}_{i j}$ (Fig. 2 下段) を与えた際, 循環流量 $Q_{r j} v_{r j}$ の算出経過 $\left(c_{j}(\xi)\right.$ の各近似成分を使用) を示す. 本例により, $c_{j}(\xi)$ 第 $m$ 次近似成分が循環流量成分 ((77) 式の第 $m$ 項) を与える機能 (Fig. 3), および, 各循環流量成分を加算して循環流量 $Q_{r j} \boldsymbol{v}_{r j}$ （Fig. 2 下 段）を求める機能の有効性を確認できる.

\subsection{3 通過流量の算出}

第 $j$ 番目の分級機構の通過流量 $Q_{t j} v_{t j}$ の算出は, 3.3.1, 3.3 .2 (循環流量の算出) の諸式中の部分分級効率 $c(\xi)$ を $\{1-c(\xi)\}$ 亿置き替え, 同様の手順で算出できる.

$$
Q_{t j} \boldsymbol{v}_{t j}(\lambda, \rho)=J_{t j} Q_{i j} \boldsymbol{v}_{i j}\left(\mu_{i j}, \sigma_{i j}\right)
$$

乙こに, 第 $j$ 番目の分級機構通過流の算出行列 $J_{t j}$ を用 いた，ちなみに，近似手法に係わる誤差分を除き，下式
(I：単位行列) が成立する.

$$
J_{r j}+J_{t j}=I
$$

\section{4 混合機構}

混合機構の平均值関数による模擬式 ((24) 式) につ いて, 2.5.2の議論に従って Q の期待值記号を除去し, さらに, $Q v$ 型へ変換して下式を得る.

$$
\begin{aligned}
& d Q_{i 0} \boldsymbol{v}_{i 0}(\lambda, \rho) \\
& =\theta\left[\sum_{j=0}^{n} Q_{r j} \boldsymbol{v}_{r j}(\lambda, \rho)-Q_{i 0} \boldsymbol{v}_{i 0}(\lambda, \rho)\right. \\
& \left.\quad+u \boldsymbol{v}_{i b}(\lambda, \rho)\right] d t+\boldsymbol{v}_{i b}(\lambda, \rho) d \beta
\end{aligned}
$$

$3.2,3.3$ の議論に従い, 第 $j$ 番目の分級機構 $(j=0$, $1, \cdots, n)$ の循環流 $Q_{r j} \boldsymbol{v}_{r j}$ を $Q_{i 0} \boldsymbol{v}_{i 0}$ で記述して本式に代 入し，系全体の低次元化したモデル化を完結できる.

\section{5 低次元化したシステム方程式}

\subsection{1 確率微分方程式による表記}

本項では，粉砕機の低次元化したモデルをシステム方 程式に整理する．乙れは $Q_{i p} v_{i p}$ を状態ベクトルとして 下式（本項以降，簡明化のため，v の基準化パラメータ $(\lambda, \rho)$ を省略）に帰着する.

$$
\begin{aligned}
& d Q_{i p} \boldsymbol{v}_{i p}= {\left[Q_{i p} \boldsymbol{a}^{\#}\left(\boldsymbol{v}_{i p}\right)+u B^{\#} \boldsymbol{v}_{i b}\right] d t } \\
&+B^{\#} \boldsymbol{v}_{i b} d \beta \\
& Q_{t 2} \boldsymbol{v}_{t 2}=Q_{i p} \eta^{\#}\left(\boldsymbol{v}_{i p}\right)
\end{aligned}
$$

ここに, ベクトル関数 $\boldsymbol{a}^{\#}, \boldsymbol{\eta}^{\#}$, 行列 $B^{\#}$ を定義した.

$$
\begin{aligned}
& \boldsymbol{a}^{\#}\left(\boldsymbol{v}_{i p}\right) \equiv \theta J_{t 0}\left[-\boldsymbol{v}_{i p}+\left(J_{r 2} J_{t 1}+J_{r 1}\right) \boldsymbol{v}_{o p}\left(\boldsymbol{v}_{i p}\right)\right] \\
& B^{\#} \equiv \theta J_{t 0} \\
& \boldsymbol{\eta}^{\#}\left(\boldsymbol{v}_{i p}\right) \equiv J_{t 2} J_{t 1} \boldsymbol{v}_{o p}\left(\boldsymbol{v}_{i p}\right)
\end{aligned}
$$

2.5.2 と同様の議論により, $\boldsymbol{a}^{\#}, \boldsymbol{\eta}^{\#}, B^{\#}$ は $Q$ に非依存で あり, (82), (83) 式は $Q$ について線形時変ガウス性の システムを記述する.

\subsection{2 平均值関数と分散関数}

本研究による粉砕機モデルの解析は, 3.5.1の議論に より, 次の平均值関数と分散関数の導出に帰着する.

$$
\begin{aligned}
& d E\left\{Q_{i p}\right\} \boldsymbol{v}_{i p} \\
& =\left[E\left\{Q_{i p}\right\} \boldsymbol{a}^{\#}\left(\boldsymbol{v}_{i p}\right)+u B^{\#} \boldsymbol{v}_{i b}\right] d t \\
& E\left\{Q_{t 2}\right\} v_{t 2}=E\left\{Q_{i p}\right\} \eta^{\#}\left(v_{i p}\right) \\
& d\left[\operatorname{Var}\left\{Q_{i p}\right\} V_{i p}\right] \\
& =\left[\operatorname{Var}\left\{Q_{i p}\right\}\left[A^{\#} V_{i p}+V_{i p} A^{\# \mathrm{~T}}\right]\right. \\
& \left.+R_{W} B^{\sharp} V_{i b} B^{\sharp \mathrm{T}}\right] d t
\end{aligned}
$$




$$
\begin{aligned}
V & \equiv \boldsymbol{v} \boldsymbol{v}^{\mathrm{T}} \quad \text { (各添字とも) } \\
A^{\#} & \equiv\left[\frac{\partial q \boldsymbol{a}^{\#}(\boldsymbol{v})}{\partial q \boldsymbol{v}}\right] \\
& =q\left[\frac{\partial \boldsymbol{a}^{\#}(\boldsymbol{v})}{\partial \boldsymbol{v}}\right]\left[\frac{\partial \boldsymbol{v}}{\partial q \boldsymbol{v}}\right]+\boldsymbol{a}^{\#}(\boldsymbol{v})\left[\frac{\partial q}{\partial q}\right]\left[\frac{\partial q}{\partial q \boldsymbol{v}}\right] \\
& =\left[\frac{\partial \boldsymbol{a}^{\sharp}(\boldsymbol{v})}{\partial \boldsymbol{v}}\right]+\boldsymbol{a}^{\sharp}(\boldsymbol{v})\left(1, v_{1}^{-1}, \cdots, v_{\nu}^{-1}\right) \\
C^{\#} & \equiv\left[\frac{\partial q \boldsymbol{\eta}^{\#}(\boldsymbol{v})}{\partial q \boldsymbol{v}}\right] \\
& =\left[\frac{\partial \boldsymbol{\eta}^{\#}(\boldsymbol{v})}{\partial \boldsymbol{v}}\right]+\boldsymbol{\eta}^{\#}(\boldsymbol{v})\left(1, v_{1}^{-1}, \cdots, v_{\nu}^{-1}\right)
\end{aligned}
$$

\section{4. モデルの検証}

本節では, 本研究による粉砕機のモデル化手法の検証 にあたり, 平均值関数（(87),（88）式）の時間応答を 具体的に求め, これを検討する.

\section{1 平均值関数の時間離散化}

本項では (87),（88）式を以下のとおり時間離散化す る.

$$
\begin{aligned}
& {\left[E\left\{Q_{i p}\right\} \boldsymbol{v}_{i p}\right]_{\tau+1}=\Phi_{\tau}\left[E\left\{Q_{i p}\right\} \boldsymbol{v}_{i p}\right]_{\tau}+u_{\tau} \Psi_{\tau} \boldsymbol{v}_{i b}} \\
& +\Delta t\left[E\left\{Q_{i p}\right\}\left\{\boldsymbol{a}^{\#}\left(\boldsymbol{v}_{i p}\right)-A^{\#} \boldsymbol{v}_{i p}\right\}\right]_{\tau}
\end{aligned}
$$

$$
\left[E\left\{Q_{t 2}\right\}_{\boldsymbol{v}_{t 2}}\right]_{\tau}=\left[E\left\{Q_{i p}\right\} \boldsymbol{\eta}^{\#}\left(\boldsymbol{v}_{i p}\right)\right]_{\tau}
$$

こてに, 添字 $\tau$ は時刻 $t=\tau \Delta t$ ( $\Delta t:$ 計算時間刻み） の值を示す. また, 2 次のパディ近似により推移行列 $\Phi_{\tau}$, 駆動行列 $\Psi_{\tau}\left(u_{\tau}: 0\right.$ 次ホールドを仮定）を求めた.

$$
\begin{aligned}
\Phi_{\tau} & \equiv \exp \left\{\Delta t A_{\tau}^{\sharp}\right\} \\
& =\left[I-0.5 \Delta t A_{\tau}^{\sharp}\right]^{-1}\left[I+0.5 \Delta t A_{\tau}^{\#}\right] \\
\Psi_{\tau} & =\left[\Phi_{\tau}-I\right]\left(A_{\tau}^{\#}\right)^{-1} B^{\#} \\
& =\Delta t\left[I-0.5 \Delta t A_{\tau}^{\sharp}\right]^{-1} B^{\sharp}
\end{aligned}
$$

なお，モーメント $\boldsymbol{v}$ の基準化は次のと抲りする.

$$
(\lambda, \rho)=\left(\mu_{i p \tau}, \sigma_{i p \tau}\right)
$$

したがって，(94），(95）式の逐次計算により，求める時 間応答が得られる.

\section{2 実プラントの応答の解析例}

発電用ボイラ向け大型石炭粉砕機 (Fig. 1 の構造) の 起動停止について, Fig. 4〜6に本論の解析手法の実施 例を紹介する. 本例では, Fig. 4 亿操作量（給炭量, 搬送空気流量）の時間変化，その際の出炭流量，保有炭 量, 出炭の粒度分布（基準粒径の $4,1,1 / 4$ 倍以下の 重量割合）の応答を，また，Fig. 5, 6亿，それぞれ， 起動操作開始直後 (時点 $(P)$ ) 起動完了後 (時点 $(\mathrm{Q})$ ) に打りる給炭, 保有炭 (仮想分級機構入口), 一次分級 機構通過, 出炭 (二次分級機構通過) の粒度分布密度関

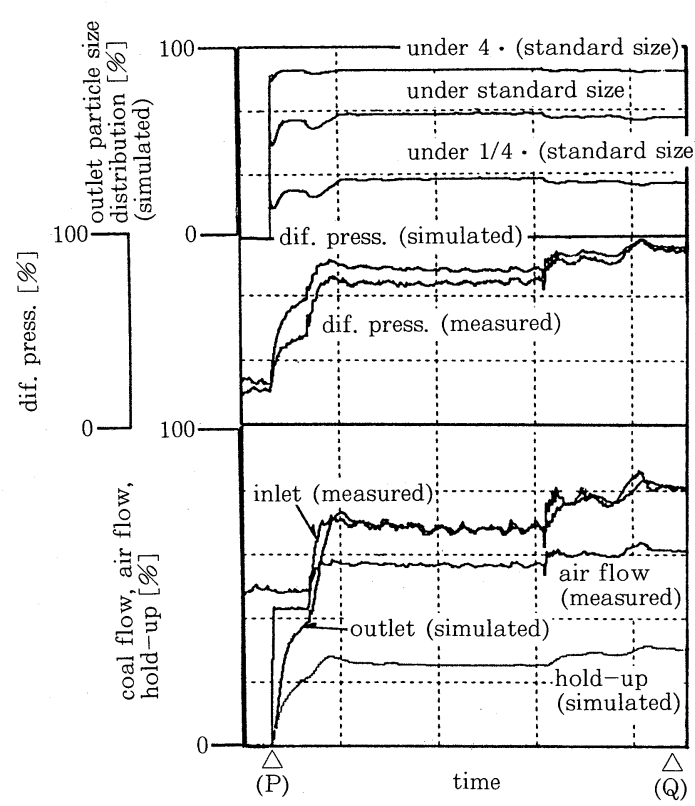

(a) start-up operation

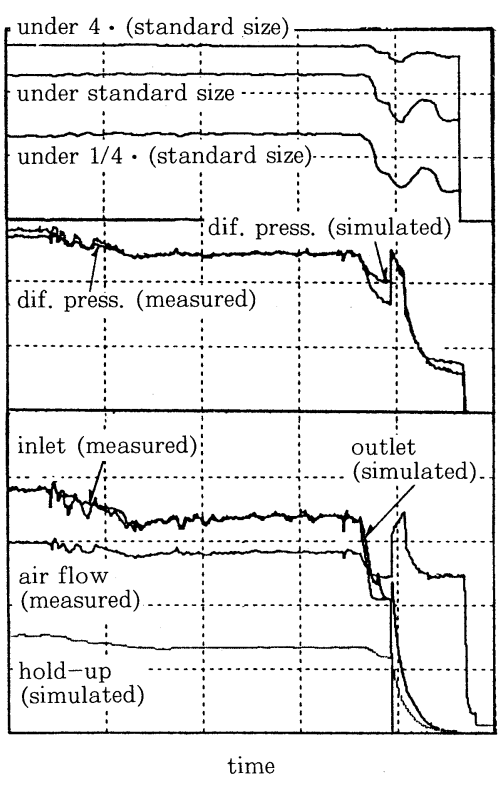

(b) shut-down operation

Fig. 4 Example of start-up and shut-down analysis for an actual pulverizer 


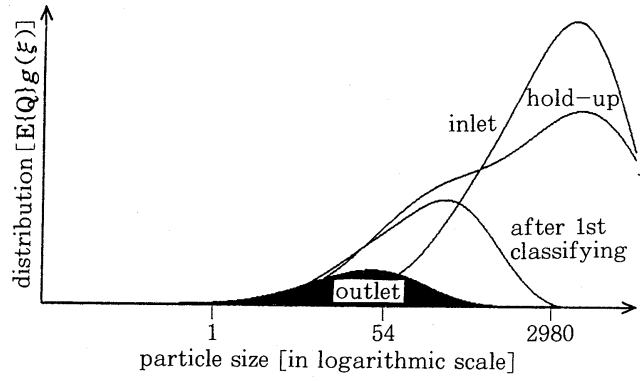

Fig. 5 Particle size distributions at the point (P)

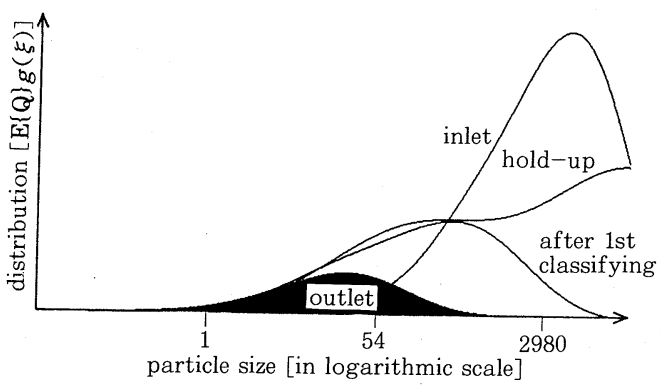

Fig. 6 Particle size distributions at the point (Q)

数（後二者の面積は当該時点の一次分級機構入口に対す る流量期侍值の比を与える）を示している．乙れらより， 粉砕機の起動停止時に打ける大幅な流量，粒度分布変化 の解析に際しても，本論の手法の良好な適用性を確認で きる.な扔，本例では計算刻み $(\Delta t) 1$ 秒で十分な数值 演算の安定性が確保でき，乙の場合，解析所要時間はパ ソコン (i-286 MPU, $12 \mathrm{MHz}$, 実数演算プロセッサ付) 利用で実時間の $1 / 5$ 程度に収まる。

大型石炭粉砕機の場合，非定常状態の出炭流量の実測 が困難なため，搬送空気入口之二次分級機構入口間の差 圧（一般に粉砕機差圧之呼ばれる；Fig. 1参照）に着目 して運転状態の監視が行われている. 当該差圧の挙動に ついて，モデル上は保有炭量（系のマスバランスの帰結） 之搬送空気流量による実験式で算出可能であり, 実測伹 と共に，乙れを Fig. 4 中段に示す. 本図より，粉砕機 差圧の模擬精度は実用上十分であり，本解析手法の妥当 性を例証できる.

\section{3 パイロット粉砕機による検証}

本解析手法の精度検証にあたり，パイロット粉砝機 （実用機の約 1/6 の規模）により, 出炭流量，粒度分布 の計算値と実測值との比較試験を行った．Fig. 7, 8 は, それぞれ，給炭量 (coal feeder 速度) 指令ステップ下 降，上昇の際のデータである. 両図中の出炭流量実測値
は差圧式 (differential pressure type : 拡大管・縮小 管それぞれの差圧から流量算出）上蓄積式（hopper type: 微粉炭ホッパの重量変化速度から流量算出)の 微粉炭流量計により, 基準粒径以下の重量割合の実測値 は規定の篩 (ふるい) を用いて求めている.

Fig. 7, 8 亿扔いて, 差圧式, 蓄積式の出炭流量計測 値の変動成分が大であり，乙れらは両計測法に起因する 雑音の影響と考えられる．したがって，両計測値の変動 の中心を想定すれば，乙れらは出炭流量計算值（平均值 関数）とおお打む致（蓄積式流量計は最後流部にあり， 遅れの影響を考慮要）して扔り，本解析手法の実用精度 達成を確認できる。また，基準粒径以下の重量割合（粒 度分布評価の目安）の計算精度も良好で，乙とに分級機 構の模擬の妥当性を示している.

\section{5.おわりに}

本論では，システム制御理論の応用に適する粉砕機の 動特性モデルの開発にあたり, 次の事項について述べた。

（1）粉体粒度分布非ガウス性の状態空間表現，および, 乙の場合の粉砕機の定式化

（2）粉体粒度分布のモーメントに着目した状態ベクトル の次数低減，および，乙の場合の粉研機内の粉砕， 分級, 混合機構の模擬方法

（3）実機特性の解析，パイロット粉砕機による動特性試 験を通じた，本モデルの妥当性確認

\section{参 考 文 献}

1) L. G. Austin et al.: An Analysis of Ball-and-Race Milling, Part I. The Harderove Mill ; Power Technology, Vol. 29, pp. 263 275 (1981)

2) L. G. Austin et al.: An Analysis of Ball-and-Race Milling, Part II. The Babcock E1. 7 Mill ; Power Technology, Vol. 33, pp. 113 125 (1982)

3) L. G. Austin et al.: An Analysis of Ball-and-Race Milling, Part III. Scale-up to Industrial Mills ; Power Technology, Vol. 33, pp. 127 134 (1982)

4) K. Shoji et al. : A Mathematical Model for a Ringroller Mill ; Proc. JSME-ASME ICOPE-93, Vol. 2, pp. 565 571 (1993)

5) N. Meguri et al. : The Development of a Ring Ball Mill Simulation Model ; KONA Powder Science and Technology in Japan, No. 7, pp. 50 58 (1989)

6) H. Cramer : Mathematical Methods of Statistics, Princeton Univ. Press (1974)

7) J. L. Doob : Stochastic Processes, John Wiley \& Sons (1953)

8）深山：キュムラントを用いた粉砕機のモデリング；第 24 回確率システム シンポジウム予稿集，pp. 189 192 (1992)

9) A. H. Jazwinski : Stochastic Process and Filtering Theory, Academic Press (1970) 


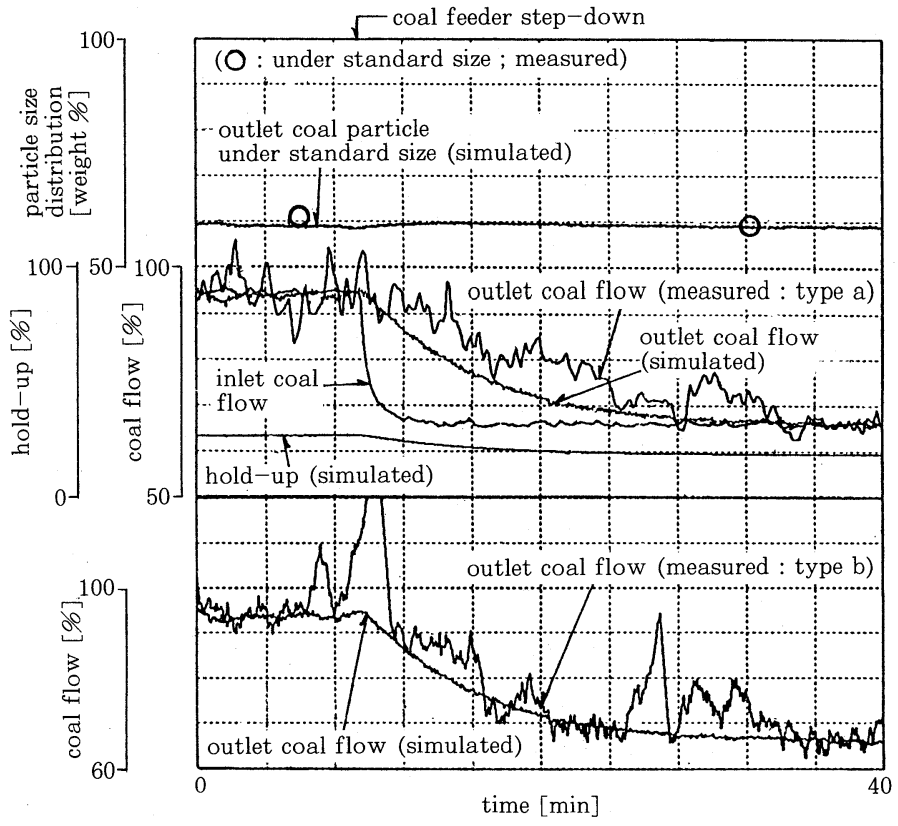

note) type a : hopper flow meter

type $b$ : differential pressure flow meter

Fig. 7 Validation on a pilot plant data (coal feeder step-down)

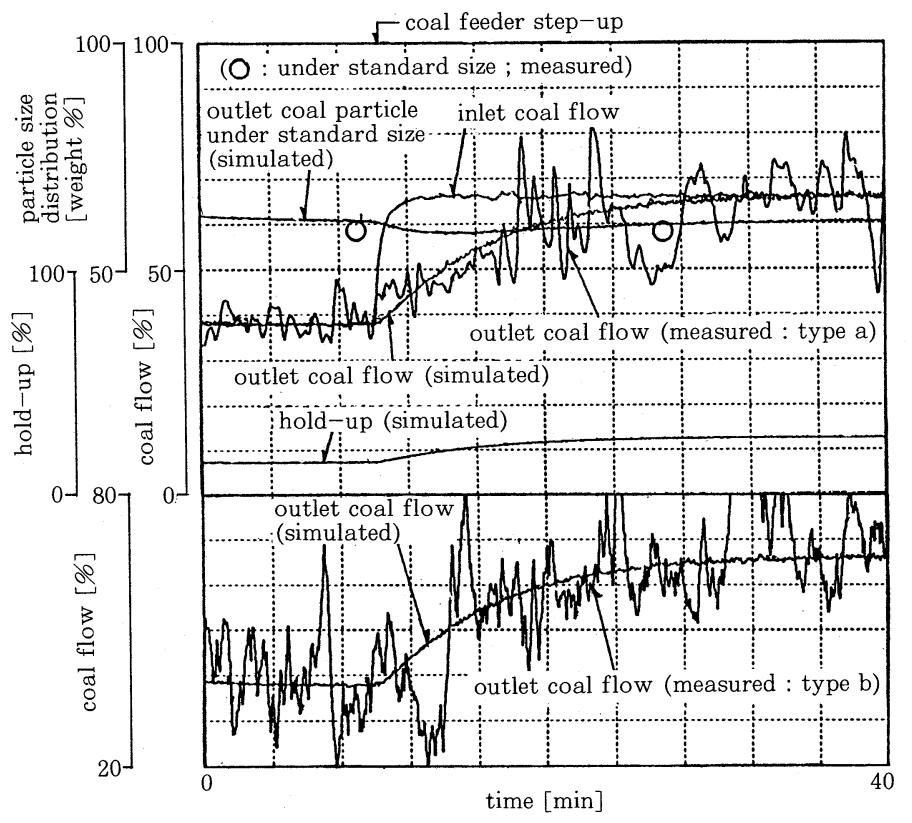

note) type a : hopper flow meter

type $b$ : differential pressure flow meter

Fig. 8 Validation on a pilot plant data 
